\title{
The Effect of Neural Mobilization with Cervical Traction in Cervical Radiculopathy Patients
}

\section{Authors \\ Kattela Suneel Kumar ${ }^{1}$, Achyutha Kiran Kumar ${ }^{2}$, Thiruppathi Arjunan ${ }^{3}$, SK Thoufiq ${ }^{4}$}

\begin{abstract}
Background: Cervical Traction and Neural Mobilization both have been individually advocated for treatment of cervical radiculopathy due to their various effects. But the combined effect of these techniques applied simultaneously has not been explored in studies. Hence the purpose is to find the effect of simultaneous application of cervical traction and neural mobilization on improvement in neck pain, radicular symptoms and neck disability in subjects with Cervical Radiculopathy.

Methods: An experimental study design, 60 subjects with Unilateral Cervical Radiculopathy and ULTT1 (Upper Limb Tension Test) positive for median nerve bias, randomized 20 subjects each into three groupsGroup A, B and C respectively. Group A received both Cervical Traction and Neural Mobilization. The Group B received only Mechanical Cervical Traction. The Group C received only Neural Mobilization. The duration of intervention was given 3 treatment sessions per week for four weeks. Outcome measures such as Numerical Pain Rating Scale, Global Rating of Change Scale, Neck Disability Index were measured before, at the end of 2 nd and 4 th week post treatment.

Results: Comparison of post intervention means at 2 nd and 4th week of treatment there is a statistically significant $(p<0.05)$ difference in improvement in outcome measures between three groups. Group A subjects shown greater percentage of improvement than Group B and Group C.

Conclusion: The present study concludes that simultaneous application of mechanical cervical traction with neural mobilization is more effective in improving pain, functional disability and severity of radicular symptoms than mechanical cervical traction and neural mobilization alone for subjects with unilateral cervical radiculopathy.

Keywords: Cervical Radiculopathy, Neck Pain, Median Nerve, Cervical Traction, Neural Mobilization, Pain, Neck Disability, Global Rating.
\end{abstract}

\section{Introduction}

Cervical radiculopathy $(\mathrm{CR})$ is, a disorder of the cervical nerve root (CNR) and most commonly is caused by a cervical disc herniation, spondylotic spur or cervical osteophyte or other spaceoccupying lesion, resulting in nerve root inflammation, impingement or both which may lead to chronic pain and disability ${ }^{1,2,3}$ The average annual incidence rate of cervical radiculopathy is
83 per 100000 for the population in its entirety, with an increased prevalence occurring in the fifth decade of life (203 per 100 000). ${ }^{4,5}$ The location and pattern of symptoms in Cervical radiculopathy vary depending on nerve root level affected and primarily presents with sensory symptoms into the upper limb such as pain, numbness, tingling sensation; motor symptoms like muscle weakness; and reflex hypo activity which often result in 
significant functional limitations and disability. ${ }^{6,7}$ Treatment techniques such as Cervical Traction and Neural Mobilization both have been individually advocated for treatment of Cervical radiculopathy due to their various effects ${ }^{8}$. Neural tissue mobilization techniques (NMTs) theorize to examine the neural tension in nerves and mobilize the nerves that exhibit neural tension by passive or active movements by using Tensioning, Sliding and Single Joint Movement techniques and focused on restoring the ability of the nervous system to tolerate the normal compressive, friction, and tensile forces associated with daily and sport activities ${ }^{8,9}$. With this method, tension was gently applied to the involved nerve root that caused mild pulling but no pain and a low amplitude repetitive movement was introduced in the direction of perceived neural tension. NMTs are widely used to normalize the CNR's structure and function by reducing nerve adherence, facilitating nerve gliding and decreasing neural mechanosensitivity in patients with cervical radiculopathy $9,10,11$.

Mechanical cervical traction is technique used to decompress the nerve root by separating the cervical segments through long-axis traction. Many studies reveals that Intermittent Cervical traction for cervical radiculopathy found to be effective in reduction of pain and disability ${ }^{12,13,14}$; however, no standard parameters have been reported. It is speculated that improvements in symptoms are due to distraction of articular surfaces by traction which unloads the components of the spine by stretching muscles, ligaments and functional units ${ }^{14-17}$. Cervical traction and neural mobilization techniques (NMTs) have been advocated in the management of CR due to their immediate analgesic effect.1219 The analgesic effect of these two techniques has been explored and recognized in many RCT studies and in systematic reviews ${ }^{12-18}$. The present study was to find out whether the simultaneous application of Cervical Traction and Neural Mobilization does have effect on improving neck pain, radicular symptoms and neck disability in subjects with unilateral cervical radiculopathy? Hence, the purpose of study with objective is to find the effect of simultaneous application of cervical traction and neural mobilization on improving neck pain, radicular symptoms and neck disability in subjects with Cervical Radiculopathy. It was hypothesised that Simultaneous application of cervical traction and neural mobilization will have a significant difference on improving neck pain, radicular symptoms and neck disability in subjects with unilateral cervical radiculopathy.

\section{Methodology}

A repeated measures experimental study design with three groups. As this study involved human subjects the Ethical Clearance was obtained from the Ethical Committee of Narayana Medical Institutions. Subjects included were both sex with age group between 45 to 55 years $^{12}$, with history of neck pain associated with radicular pain below the occiput and unilateral side of the neck with a tingling sensation occurring on the lateral aspect of the elbow joint, ${ }^{3}$ positive for the test item cluster for provocative Tests which include the Spurling's test, Shoulder Abduction test, Valsalva Maneuver, Neck Distraction test and Upper limb tension test, ${ }^{3}$ positive history from the Six historical questions diagnostic for Cervical Radiculopathy $^{3}$ which include the following questions:

1) Which are your most bothersome symptoms: Pain, Numbness / Tingling, Loss of feeling.

2) Where are the symptoms most bothersome: Neck, Shoulder, Scapula, Arm above elbow, Arm below elbow, Hand, Fingers.

3) Symptom behaviour - Constant, Intermittent, Variable.

4) Entire limb numbness.

5) Are the symptoms keeping you away from sleep?

6) Does the neck movement improve or worsen the arm pain. 
7) Complaints of pain radiating to Upper Extremity that was provoked or exacerbated by

Cervical Range of Motion, ${ }^{14}$ Paraesthesia in dermatomal pattern (for Median Nerve), ${ }^{20}$ mild to moderate severity of radicular symptoms measured by Visual Analogue Scale between 5 to $7 \mathrm{~cm}$, subjects having clear or unequivocal relief of the radicular pain with the manual cervical distraction test, ${ }^{14}$ and positive for ULTT1, Median Nerve Bias. $^{21}$ Subjects excluded were with sensory loss or motor weakness due to cervical radiculopathy, history of trauma, rheumatoid arthritis, malignancy, cervical Instability, ${ }^{15}$ cord myelopathy, vertebro-basilar syndrome, undiagnosed pain, who has undergone cervical surgeries, bilateral radiculopathy, neuropathies etc. Total 60 Subject $(n=60)$ who meet the inclusion criteria were recruited by Simple random sampling method using closed envelops, randomly allocated 20 subjects into each Group A, B, and C. Subjects who meet inclusion criteria were informed about the study and a written informed consent was taken. Total four weeks of intervention with 12 treatment sessions which includes 3 treatment sessions in a week was given. ${ }^{15}$

\section{Procedure of Intervention for Group A}

In this group subjects were treated simultaneously with mechanical cervical traction and neural mobilization. Calibrated Biomed Traction unit was used in the study. For Intermittent Cervical Traction subjects were instructed about the procedure and were taken in supine on the treatment couch with the body in neutral position. The cervical spine was placed at an angle of approximately 15 degrees of flexion with traction force to be $10 \%$ of subject's body weight and was increased approximately $1 \mathrm{~kg}$ every visit, depending on centralization or reduction of symptoms and on/off cycle set at 60/30 seconds) and treatment was given for 9 minutes per session. ${ }^{15,20,22}$ A buzar switch in the unaffected arm was given so that subject can alert the therapist in case of any discomfort during traction and neural mobilization. After starting the traction machine, neural mobilization procedure was performed. The therapist stood on the affected side besides the subject and depressed the subject's shoulder with one hand while the elbow would be kept in 90 degrees of flexion and forearm in supination and wrist and fingers in extended position using other hand. Then subject's arm was passively taken into 90 to 100 degrees of abduction (as tolerable by the subject). This was followed by either the sliding or the gliding procedure. If sliding of the nerve was to be done then alteration of elbow extension (loading median nerve) with wrist flexion (unloading median nerve) and elbow flexion (unloading median nerve) with wrist extension (loading median nerve) was performed for 6 sets of repetitions. Each set was performed in a slow oscillatory manner during the pull time of the traction (60 seconds) followed by 30 seconds rest. 23 In the 60 seconds each time first 3 sets of sliding followed by 3 sets of gliding were given, followed by 30 seconds rest. As the symptoms improved the patient was progressed to gliding/ tensioning technique. ${ }^{24}$

\section{Procedure of Intervention for Group B}

In this group subjects were treated with only mechanical cervical traction. The Procedure for giving traction was followed same as given in Group A, but no neural mobilization was given along with it.

\section{Procedure of Intervention for Group C}

In this group subjects were treated with only neural mobilization (median nerve). The procedure of applying neural mobilization was the same as given in Group A, but no traction was applied.

\section{Outcome Measures}

Outcome measures were measured before at the end of 2nd and 4th week of treatment.

Pain as recorded by NPRS (Numerical Pain Rating Scale): Subjects was asked to mark 
anywhere on the scale from 0 to 10 which best describes his/ her pain intensity. The mark was recorded using a measuring scale (in $\mathrm{cm}$ ) to measure the marked point and the obtained NPRS Score was recorded and used for analysis. The Severity of Radicular Symptoms was recorded by the GROC (Global Rating of Change Scale) which is a self administered scale, being filled in by participants themselves. The patient has to rate his/her overall radiculopathy condition from the time that the treatment began until now by marking on any of the numbers from -7 to 7 , where it starts from worse i.e. negative to better. The Functional Disability was recorded by NDI (Neck Disability Index) which consists of 10 sections which have Questions that give information as to how the neck pain has affected the ability to manage in everyday life. Each section was scored on a 0 to 5 scale with first statement being 0 (i.e. No pain) and last statement being 5 (i.e. worst imaginable pain). Higher score indicates participant has more disability. The Neck Disability Index and Numeric Pain Rating Scale exhibited fair test-retest reliability, with adequate responsiveness in patient with cervical radiculopathy. ${ }^{25}$ The NDI is the most widely used and most strongly validated instrument for assessing self-rated disability in patients with neck pain. ${ }^{26}$ Global Rating of Change Scale offers a flexible, quick and simple method of charting self assessed clinical progress in research and clinical settings and has clinical relevance, adequate reproducibility and sensitivity to changes. Test retest reliability was found to be high (ICC 0.9) and face validity (0.90).

\section{Data Analysis}

Descriptive statistical analysis carried out in the present study. Out Come measurements assessed at $5 \%$ level of significance with $p$ value was set at 0.05 less than this is considered as statistically significant difference. Repeated Measures Analysis of Variance was used for within the group analysis and Bonferroni's as post-hoc test was used to find the significance in pair-wise comparison. One-way ANOVA and Tukey HD post-hoc test and Kruskal-Wallis Test have been used to compare the means of variables between the three groups and multiple pair-wise comparisons with calculation of percentage of difference between the means. The Statistical software namely SPSS 16.0, Stata 8.0, MedCalc 9.0.1 and Systat 11.0 were used for the analysis of the data and Microsoft word and Excel have been used to generate graphs, tables etc.

\section{Results}

Total 60 subjects were studied, in Group A there were 20 subjects with mean age 50.55 years, in Group B there were 20 subjects with mean age 49.70 years and in Group $C$ there were 20 subjects with mean age 49.90 years. Within the group analysis of outcome measures in Group A, Group $\mathrm{B}$, and Group $\mathrm{C}$ shows that there is a statistically significant change in means of NPRS and NDI when means were analyzed from pre intervention to 2 nd week intervention and to 4 weeks post intervention measurements within the groups.

There is a clinical significance effect with large effect size. Analysis of severity of radicular Symptoms between the groups found that Group A shown greater percentage of reduction in severity of radicular Symptoms that Group B and C. In Group A the severity of radicular Symptoms was recorded by the GROC scale before intervention there were $35 \%$ of subjects had a condition of 'Quite a bit worse', 30\% of subjects were 'Moderately worse', $20 \%$ of subjects were with 'Somewhat worse' and15\% subjects with 'A little bit worse'. In Group A after 2 weeks of intervention $10 \%$ of subjects were with condition 'Somewhat worse', 25\% of subjects with a 'A little bit worse', $15 \%$ of subjects with 'A tiny bit worse', $25 \%$ of subjects with a 'A tiny bit better', $25 \%$ of subjects with 'A little bit better'.

After 4 weeks of intervention $15 \%$ of subjects with 'A tiny bit worse', $20 \%$ of subjects with 'A tiny bit better', $5 \%$ of subjects with 'A little bit better' $15 \%$ of subjects with 'somewhat better', $20 \%$ of subjects with 'Moderately better', $20 \%$ of 


\section{JMSCR Vol||05||Issue ||05||Page 22078-22087||May}

subjects with Quite a bit better, 5\% of subjects with 'A great deal better'. In Group B the severity of radicular Symptoms was recorded by the GROC scale before intervention there before intervention there were $40 \%$ of subjects had a condition of 'moderate worse', 25\% of subjects were 'Somewhat worse', $10 \%$ of subjects were 'A little bit worse'. In Group B after 2 weeks of intervention $10 \%$ of subjects were with condition 'Somewhat worse', $25 \%$ of subjects with a 'A little bit worse', $40 \%$ of subjects with 'A tiny bit worse', $25 \%$ of subjects with a 'A tiny bit better'. After 4 weeks of intervention $10 \%$ of subjects with 'A tiny bit worse', $25 \%$ of subjects with 'A tiny bit better', $30 \%$ of subjects with 'A little bit better', $25 \%$ of subjects with 'somewhat better', $10 \%$ of subjects with 'Moderately better'.

In Group $\mathrm{C}$ the severity of radicular Symptoms before intervention there were $25 \%$ of subjects had a condition of 'Quite a bit worse', 30\% of subjects were 'Moderately worse', 25\% of subjects were with 'Somewhat worse' and 20\% subjects with 'A little bit worse'. In Group C after 2 weeks of intervention $20 \%$ of subjects were with condition 'Somewhat worse', 35\% of subjects with a 'A little bit worse', $25 \%$ of subjects with 'A tiny bit worse', $20 \%$ of subjects with a 'A tiny bit better'. After 4 weeks of intervention $15 \%$ of subjects with 'A tiny bit worse', $20 \%$ of subjects with 'A tiny bit better', $20 \%$ of subjects with 'A little bit better', $35 \%$ of subjects with 'somewhat better', $10 \%$ of subjects with 'Moderately better'. The NPRS and NDI means were compared between the three groups. Before intervention shows that there was no statistically significant difference between the groups at pre-intervention and 2nd week post intervention. When the means were compared at 4th week post-intervention shown that there was a statistically significant difference between the groups $\mathrm{A}$ and $\mathrm{B}$, and Group $\mathrm{A}$ and $\mathrm{C}$ and there is no statistically significant difference between the Group B and C.

Table: 1 Analysis of NPRS and NDI within the Group A (Repeated measures analysis)

\begin{tabular}{|l|c|c|c|}
\hline \multirow{2}{*}{ Study Study Group Group } & Pre intervention & 2nd week & 4th week \\
\hline \multirow{2}{*}{ NPRS } & $\begin{array}{c}\text { Mean } \pm \text { SD }) \\
\text { min-max }\end{array}$ & $\begin{array}{c}(\text { Mean } \pm \text { SD }) \\
\text { min-max }\end{array}$ & $\begin{array}{c}\text { (Mean } \pm \text { SD }) \\
\text { min-max }\end{array}$ \\
\cline { 2 - 4 } Neck Disability & $6.14 \pm 0.62$ & $4.25 \pm 0.90$ & $1.76 \pm 0.65$ \\
\hline Index in \% & $49.1-6.9)$ & $(2.4-5.8)$ & $(1.1-3.3)$ \\
\hline
\end{tabular}

** Statistically Significant difference $\mathrm{p}<0.05$; NS- Not significant; a. Friedman's ANOVA.

\begin{tabular}{|c|c|c|c|c|c|c|c|}
\hline & & \multirow{2}{*}{$\begin{array}{l}\text { Percentage } \\
\text { of change }\end{array}$} & \multirow{2}{*}{ F- Value } & \multirow{2}{*}{$\begin{array}{c}\text { Significance } \\
\text { P- value }\end{array}$} & \multirow{2}{*}{ Effect size $r$} & \multicolumn{2}{|c|}{$\begin{array}{l}95 \% \text { Confidence Interval } \\
\text { for Difference }\end{array}$} \\
\hline & & & & & & $\begin{array}{l}\text { Lower } \\
\text { Bound } \\
\end{array}$ & $\begin{array}{l}\text { Upper } \\
\text { Bound }\end{array}$ \\
\hline \multirow{3}{*}{$\begin{array}{l}\text { NPRS } \\
\text { NPRS }\end{array}$} & $\begin{array}{l}\text { Pre to } 2 \text { nd } \\
\text { week }\end{array}$ & $-30.78 \%$ & 183.31 & $\mathrm{P}=0.000^{* *}$ & +0.77 (Large) & 5.84 & 6.43 \\
\hline & $\begin{array}{l}\text { 2nd week to } \\
\text { 4th week }\end{array}$ & $-58.58 \%$ & 234.71 & $\mathrm{P}=0.000^{* *}$ & +0.84 (Large) & 3.83 & 4.67 \\
\hline & $\begin{array}{l}\text { Pre to } 4 \text { th } \\
\text { week }\end{array}$ & $-71.33 \%$ & 972.71 & $\mathrm{P}=0.000 * *$ & $+0.96($ Large $)$ & 1.45 & 2.07 \\
\hline \multirow{3}{*}{$\begin{array}{l}\text { Neck } \\
\text { Disability } \\
\text { Index in \% }\end{array}$} & $\begin{array}{l}\text { Pre to } 2 \text { nd } \\
\text { week }\end{array}$ & $-30.76 \%$ & 104.12 & $\mathrm{P}=0.000^{* *}$ & +0.61 (Large) & 43.92 & 54.87 \\
\hline & $\begin{array}{l}\text { 2nd week to } \\
\text { 4th week }\end{array}$ & $-41.81 \%$ & 104.13 & $\mathrm{P}=0.000^{* *}$ & +0.76 (Large) & 30.66 & 37.74 \\
\hline & $\begin{array}{l}\text { Pre to } 4 \text { th } \\
\text { week }\end{array}$ & $-59.71 \%$ & 154.89 & $\mathrm{P}=0.000^{* *}$ & $+0.86($ Large $)$ & 18.06 & 21.73 \\
\hline
\end{tabular}

Adjustment for multiple comparisons Bonferroni. 
Table 2: Analysis of NPRS and NDI within the Group B (Repeated measures analysis)

\begin{tabular}{|c|c|c|c|}
\hline Study Group & $\begin{array}{l}\text { Pre intervention } \\
(\text { Mean } \pm \text { SD) } \\
\text { min-max }\end{array}$ & $\begin{array}{c}\text { 2nd week } \\
(\text { Mean } \pm \text { SD }) \\
\text { min-max }\end{array}$ & $\begin{array}{c}\text { 4th week } \\
(\text { Mean } \pm \text { SD) } \\
\text { min-max }\end{array}$ \\
\hline NPRS & $\begin{array}{c}6.28 \pm 0.51 \\
(5.2-6.9)\end{array}$ & $\begin{array}{c}4.79 \pm 0.93 \\
(2.6-6.2)\end{array}$ & $\begin{array}{c}2.83 \pm 0.87 \\
(1.1-4.3)\end{array}$ \\
\hline $\begin{array}{l}\text { Neck Disability } \\
\text { Index in } \%\end{array}$ & $\begin{array}{c}53.20 \pm 12.37 \\
(30-76) \\
\end{array}$ & $\begin{array}{c}36.90 \pm 9.30 \\
(20-52)\end{array}$ & $\begin{array}{c}25.00 \pm 6.60 \\
(14-38)\end{array}$ \\
\hline
\end{tabular}

** Statistically Significant difference $\mathrm{p}<0.05$; NS- Not significant; a. Friedman’s ANOVA.

\begin{tabular}{|c|c|c|c|c|c|c|c|}
\hline & & \multirow{2}{*}{$\begin{array}{l}\text { Percentage } \\
\text { of change }\end{array}$} & \multirow[t]{2}{*}{ F- Value } & Significance & \multirow[t]{2}{*}{ Effect size $r$} & \multicolumn{2}{|c|}{$\begin{array}{l}95 \% \text { Confidence } \\
\text { Interval } \\
\text { for Difference }\end{array}$} \\
\hline & & & & P-value & & $\begin{array}{l}\text { Lower } \\
\text { Bound }\end{array}$ & $\begin{array}{l}\text { Upper } \\
\text { Bound }\end{array}$ \\
\hline \multirow{3}{*}{$\begin{array}{l}\text { NPRS } \\
\text { NPRS }\end{array}$} & $\begin{array}{l}\text { Pre to } 2 \text { nd } \\
\text { week }\end{array}$ & $-23.72 \%$ & 109.02 & $\mathrm{P}=0.000 * *$ & $\begin{array}{c}+0.70 \\
\text { (Large) }\end{array}$ & 1.07 & 1.91 \\
\hline & $\begin{array}{c}\text { 2nd week to } \\
4 \text { th week }\end{array}$ & $-40.91 \%$ & 152.89 & $\mathrm{P}=0.000 * *$ & $\begin{array}{c}+0.73 \\
\text { (Large) } \\
\end{array}$ & 1.49 & 2.42 \\
\hline & $\begin{array}{l}\text { Pre to 4th } \\
\text { week }\end{array}$ & $-54.93 \%$ & 536.53 & $\mathrm{P}=0.000 * *$ & $\begin{array}{c}+0.92 \text { (Large } \\
\text { ) }\end{array}$ & 3.01 & 3.88 \\
\hline \multirow{3}{*}{$\begin{array}{l}\text { Neck } \\
\text { Disability } \\
\text { Index in \% }\end{array}$} & $\begin{array}{l}\text { Pre to } 2 \text { nd } \\
\text { week }\end{array}$ & $-30.63 \%$ & 182.17 & $\mathrm{P}=0.000 * *$ & $\begin{array}{c}+0.59 \text { (Large } \\
)\end{array}$ & 12.74 & 19.85 \\
\hline & $\begin{array}{c}\text { 2nd week to } \\
4 \text { th week }\end{array}$ & $-32.24 \%$ & 158.36 & $\mathrm{P}=0.000^{* *}$ & $\begin{array}{c}+0.59 \\
\text { (Large) }\end{array}$ & 9.11 & 14.68 \\
\hline & $\begin{array}{l}\text { Pre to } 4 \text { th } \\
\text { week }\end{array}$ & $-53.00 \%$ & 239.22 & $\mathrm{P}=0.000 * *$ & +0.81 (Large & 22.83 & 33.56 \\
\hline
\end{tabular}

Adjustment for multiple comparisons Bonferroni.

Table 3: Analysis of NPRS and NDI within the Group C (Repeated measures analysis)

\begin{tabular}{|c|c|c|c|}
\hline Study Group & $\begin{array}{c}\text { Pre intervention } \\
(\text { Mean } \pm \text { SD) } \\
\text { min-max }\end{array}$ & $\begin{array}{c}\text { 2nd week } \\
(\text { Mean } \pm \text { SD) } \\
\text { min-max }\end{array}$ & $\begin{array}{c}\text { 4th week } \\
(\text { Mean } \pm \text { SD) } \\
\text { min-max }\end{array}$ \\
\hline NPRS & $\begin{array}{c}6.15 \pm 0.61 \\
(5.1-6.9)\end{array}$ & $\begin{array}{c}4.70 \pm 0.88 \\
(3.1-5.8)\end{array}$ & $\begin{array}{c}2.45 \pm 1.01 \\
(1.1-4.2)\end{array}$ \\
\hline $\begin{array}{l}\text { Neck Disability } \\
\text { Index in } \%\end{array}$ & $\begin{array}{c}50.80 \pm 11.28 \\
(28-70)\end{array}$ & $\begin{array}{c}37.60 \pm 8.76 \\
(20-54)\end{array}$ & $\begin{array}{c}23.80 \pm 6.61 \\
(14-38)\end{array}$ \\
\hline
\end{tabular}

** Statistically Significant difference $\mathrm{p}<0.05$; NS- Not significant; a. Friedman’s ANOVA.

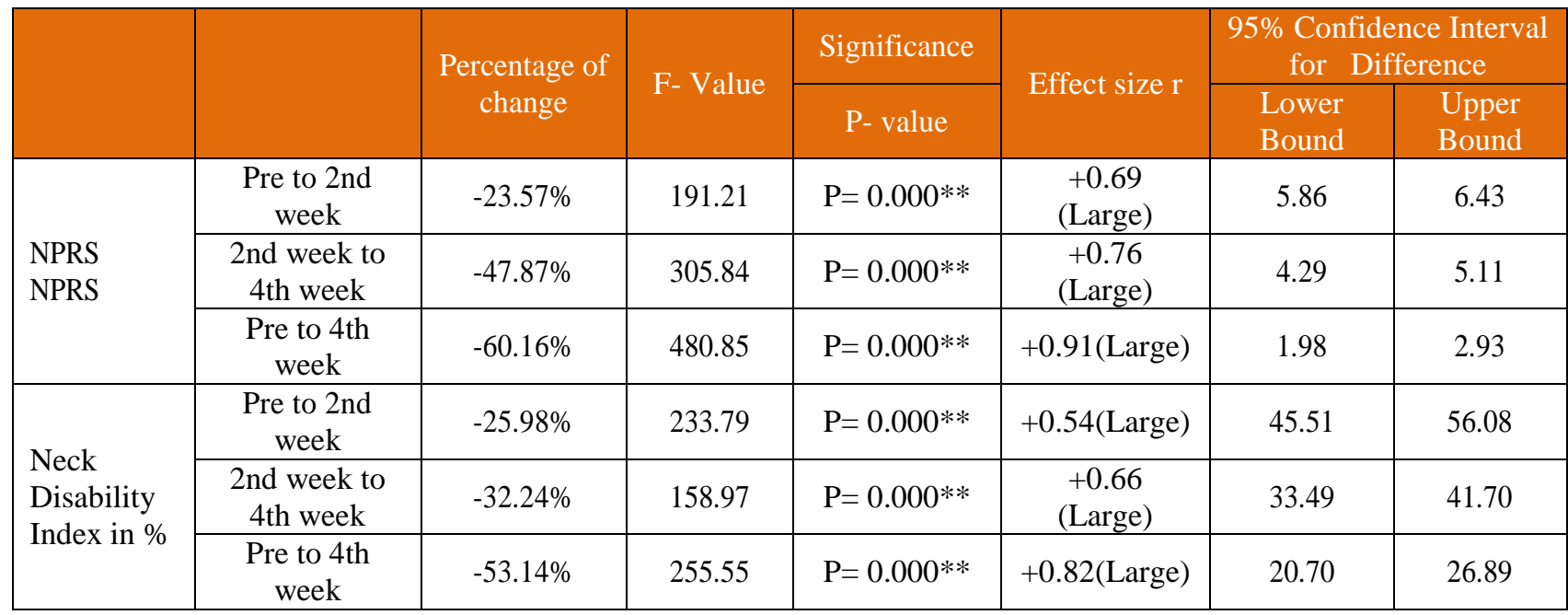

Adjustment for multiple comparisons: Bonferroni. 
Table 4: Comparison of NPRS score between the three groups -Group A, B and C

\begin{tabular}{|c|c|c|c|c|c|c|}
\hline & \multirow[t]{2}{*}{$\begin{array}{l}\text { Perecntage } \\
\text { of } \\
\text { difference }\end{array}$} & \multirow[t]{2}{*}{ Effect size $r$} & \multirow{2}{*}{$\begin{array}{c}\text { Between two } \\
\text { Groups } \\
\text { Significance } \\
\text { P- Value }\end{array}$} & \multicolumn{2}{|c|}{$\begin{array}{l}95 \% \text { Confidence } \\
\text { interval of the } \\
\text { difference }\end{array}$} & \multirow{2}{*}{$\begin{array}{l}\text { Between } \\
\text { Three } \\
\text { Groups }\end{array}$} \\
\hline & & & & Lower & Upper & \\
\hline \multicolumn{7}{|c|}{ Pre intervention NPRS Score } \\
\hline Group A and Group B & $2.25 \%$ & 0.12 Small & $\mathrm{P}=0.732(\mathrm{NS})$ & -0.587 & 0.307 & \multirow{3}{*}{$\begin{array}{c}0.396 \\
\mathrm{p}=0.820 \\
(\mathrm{NS})\end{array}$} \\
\hline Group B and Group C & $-2.09 \%$ & 0.11 Small & $\mathrm{P}=0.764(\mathrm{NS})$ & -0.317 & 0.577 & \\
\hline Group A and Group C & $0.16 \%$ & +0.00 Small & $\mathrm{P}=0.998(\mathrm{NS})$ & -0.457 & 0.437 & \\
\hline \multicolumn{7}{|l|}{ 2nd week of intervention } \\
\hline Group A and Group B & $-11.94 \%$ & +0.28 Small & $\mathrm{P}=0.158(\mathrm{NS})$ & & 0.155 & \multirow{3}{*}{$\begin{array}{c}4.002 \\
\mathrm{p}=0.135 \\
(\mathrm{NS})\end{array}$} \\
\hline Group B and Group C & $-1.89 \%$ & +0.05 Small & $\mathrm{P}=0.953(\mathrm{NS})$ & & 0.775 & \\
\hline Group A and Group C & $10.05 \%$ & +0.025 Small & $\mathrm{P}=0.267(\mathrm{NS})$ & -1.140 & 0.240 & \\
\hline \multicolumn{7}{|c|}{ 4th Post Intervention NPRS Score } \\
\hline Group A and Group B & $46.62 \%$ & +0.57 (Large) & $\mathrm{P}=0.001 * *$ & -1.719 & -.411 & \multirow{3}{*}{$\begin{array}{c}12.935 \\
\mathrm{p}=0.002 * *\end{array}$} \\
\hline Group B and Group C & $-14.39 \%$ & +0.19 (Small) & $\mathrm{P}=0.358(\mathrm{NS})$ & -0.279 & 1.029 & \\
\hline Group A and Group C & $32.85 \%$ & +0.37 (Medium) & $\mathrm{P}=0.036^{* *}$ & -1.344 & -0.036 & \\
\hline
\end{tabular}

Table 5: Comparison of NDI between the Groups A, B and C

\begin{tabular}{|c|c|c|c|c|c|c|}
\hline & \multirow[t]{2}{*}{$\begin{array}{l}\text { Perecntage } \\
\text { of } \\
\text { difference }\end{array}$} & \multirow[t]{2}{*}{ Effect size $r$} & \multirow{2}{*}{$\begin{array}{c}\text { Between two } \\
\text { Groups } \\
\text { Significance } \\
\text { P- Value }\end{array}$} & \multicolumn{2}{|c|}{$\begin{array}{c}95 \% \text { Confidence } \\
\text { interval of the } \\
\text { difference }\end{array}$} & \multirow[t]{2}{*}{$\begin{array}{c}\text { Between } \\
\text { Three } \\
\text { Groups }\end{array}$} \\
\hline & & & & Lower & Upper & \\
\hline \multicolumn{7}{|l|}{ Pre intervention NDI } \\
\hline Group A and Group B & $7.40 \%$ & 0.15 Small & $\mathrm{P}=0.568(\mathrm{NS})$ & -12.77 & 5.17 & \multirow{3}{*}{$\begin{array}{c}\mathrm{F}=0.531 \\
\mathrm{p}=0.591 \\
(\mathrm{NS})\end{array}$} \\
\hline Group B and Group C & $-62.30 \%$ & 0.10 Small & $\mathrm{P}=0.797(\mathrm{NS})$ & -6.57 & 11.37 & \\
\hline Group A and Group C & $2.79 \%$ & +0.06 Small & $\mathrm{P}=0.925(\mathrm{NS})$ & -10.37 & 7.57 & \\
\hline \multicolumn{7}{|l|}{ 2nd week of intervention } \\
\hline Group A and Group B & $7.59 \%$ & +0.15 Small & $\mathrm{P}=0.583(\mathrm{NS})$ & -9.23 & 3.83 & \multirow{3}{*}{$\begin{array}{c}\mathrm{F}=0.877 \\
\mathrm{p}=0.422 * * \\
(\mathrm{NS})\end{array}$} \\
\hline Group B and Group C & $1.87 \%$ & +0.03 Small & $\mathrm{P}=0.964(\mathrm{NS})$ & -7.23 & 5.83 & \\
\hline Group A and Group C & $9.47 \%$ & +0.20 Small & $\mathrm{P}=0.427(\mathrm{NS})$ & -9.93 & 3.13 & \\
\hline \multicolumn{7}{|l|}{ 4th Post Intervention } \\
\hline Group A and Group B & $22.71 \%$ & +0.42 (Medium) & $\mathrm{P}=0.021 * *$ & -9.55 & -.65 & \multirow{3}{*}{$\begin{array}{c}\mathrm{F}=4.154 \\
\mathrm{p}=0.021 * *\end{array}$} \\
\hline Group B and Group C & $-4.91 \%$ & $+0.06($ Small $)$ & $\mathrm{P}=0.794(\mathrm{NS})$ & -3.25 & 5.65 & \\
\hline Group A and Group C & $17.84 \%$ & +0.33(Medium) & $\mathrm{P}=0.097 * *$ & -8.35 & 0.55 & \\
\hline
\end{tabular}

\section{Discussion}

It is found from the analysis that 4 weeks of interventions consisting simultaneous application of Mechanical Cervical Traction along with Neural Mobilization for the subjects in Group A shown statistically significant greater percentage of improvement in pain, functional disability and severity of the radicular symptoms than Group B who received only Mechanical Cervical Traction and Group C who received only Neural Mobilization. In Group A subjects the improvements could be because of simultaneous application of Mechanical Cervical Traction along with Neural Mobilization. In this present study maintaining the application of cervical traction for
1 min, slider neural mobilizations was applied during traction to mobilize and restore the normal structure and function of the nerve root that causing radiculopathy. Even though there are no standard parameters have been reported for cervical traction, it is speculated that traction causes distraction of articular surfaces, unloads the components of the spine by stretching muscles, ligaments, reduce adhesions within the dural sleeve, relieve nerve root compression within the central foramina, decreases pressure within intervertebral discs, relieves tonic muscle contraction and improves vascular status within the epidural space and perineural structures. ${ }^{13-17}$ Neural tissue mobilization techniques focus on 
restoring the ability of the nervous system to tolerate the normal compressive, friction, and tensile forces associated with daily and sport activities. ${ }^{8,9}$ The techniques used in this study were tensioning technique, Sliding technique and Single Joint Movement technique which are commonly used Neural Mobilization techniques. ${ }^{28,29,30}$ Sliding techniques during traction allows large range neurally non-aggressive movements. The clinical assumption is that these sliding techniques result in a larger longitudinal excursion of the nerve with a minimal increase in strain on impinged or tensed nerve. A gliding/ tensioning technique may reduce intraneural swelling and circulatory compromise via fluctuating effects on intraneural pressure. Nerve gliding is induced by elongation of the nerve bed which elongates the nerve, increases the nerve tension and intraneural pressure reducing the intraneural blood flow in the oedematous neuropathies. Dynamically altering intraneural pressure may result in a 'pumping action' or 'milking effect' with beneficial effects on nerve hydration as it facilitates evacuation of the intra neural oedema when correctly applied and hence brings about a reduction in symptoms. ${ }^{31,32,33}$ The effects of these techniques individually have been explored in many RCTs and systematic reviews. In a single case study by Christos Savva et.al found that cervical traction combined with neural mobilization significantly shown effective in improving pain and disability in a patient with cervical radiculopathy. ${ }^{19}$ In Group B (Traction Group), there were significant improvement in post intervention measurements and this could be because of Mechanical cervical traction received for 12 sessions that might have shown decrease in pain level and perceived disability in patients with cervical radiculopathy. In Group C (Neural Mobilization Group) the improvement could be because of Neural Mobilization Techniques that used to normalize the CNRs (cervical nerve root) structure and function via the possible reduction of nerve adherence, facilitation of nerve gliding and decreased neural mechanosensitivity. ${ }^{9}$ When the NPRS score and NDI means were compared at pre-intervention and 2nd week post intervention between the groups there was no statistically significant difference between the groups. When the means of 4th week postintervention were compared between three group there was a statistically significant difference between the groups. There is significant improvement in severity of radicular Symptoms measured by Global Rating of Change Scale between the groups. Group A subjects shown greater percentage of reduction in severity of radicular Symptoms than Group B and C. These improvements were obtained without use of any conventional treatment techniques like exercises and modalities. The improvements obtained in Group A subjects were $-71.33 \%$ in NPRS and $59.71 \%$ in NDI and with greater percentage of reduction in radicular symptoms following 12 sessions of treatment during 4 weeks of duration. Therefore, based on findings it was found that the simultaneous application of mechanical cervical traction along with neural mobilization received by Group A subjects found to be more effective than the Groups B and C subjects. Therefore, the present study rejects null hypothesis.

\section{Limitations of the Study}

This study sample selection was considered age group between 45 to 55 only, thus results were not generalize the whole population. Dosage of treatment parameters of the combined treatment techniques in the study was not standardized according to individual patients. Effectiveness was based on subjective outcome measures therefore objective outcome measures were not used. The long term effect was not found.

\section{Conclusion}

The present study concludes that simultaneous application of mechanical cervical traction with neural mobilization is more effective in improving pain, functional disability and severity of radicular symptoms than mechanical cervical traction and neural mobilization alone for subjects with 
Unilateral Cervical Radiculopathy. The simultaneous application of mechanical cervical traction along with neural mobilization is recommended in the treatment of Unilateral Cervical Radiculopathy.

\section{Reference}

1. Ian A. Young, Lori A. Michener, et al. Manual Therapy, Exercise, and Traction for Patients with cervical radiculopathy: A randomized clinical trial. American Physical Therapy Association. 2009; 89: 632-642.

2. Cervical radiculopathy is a pathology of the cervical nerve root. ${ }^{16}$ It is frequently associated with cervical disc herniation or another space occupying lesion (such as osteophytes), which can cause nerve root impingement and inflammation. It mostly afflicts adults in their fourth and fif Joshua A. Cleland, Julie M. Whitman, Julie M. Fritz, Jessica A. Palmer, Manual physical therapy, Journala of orthopaedic and sports physical therapy. 2005; 35(12): 802-809

3. Ellenberg MR,Honet JC,Treanor WJ.Cervical radiculopathy.Arch Phys Med Rehabil.1994;75:342-352.

4. Farmer JC, Wisneski RJ. Cervical spine nerve root compression. An analysis of neuroforaminal pressures with varying head and arm positions. Spine. 1994; 19: 1850-158.

5. Heckmann JG, Lang CJ, Zobelein I, et al. Hearniated cervical intervertebral dics with radiculopathy: J Spinal Disorder.1999; 12: 396-401.

6. Muhle C, Bischoff L, Weinert D, et al. Exacerbated painin cervical radiculopathy at axial rotation, flexion,extension, and coupled motions of the cervical spine: evaluation by kinematic magnetic resonance imaging.Invest Radiol. 1998; 33: 279-288.

7. Joshua A Cleland, Julie M Whitmann,Julie M Fritz, Jessica A Palmer. Manual physical Therapy, Cervical traction and Strengthening exercises in patients with cervical radiculopathy - a case series. Journal of orthopedic and sports physiotherapy.2005; 35: pp 802-811.

8. Saal J S, Sall J A, Yurth E F. Non operative management of herniated cervical intervertebral radiculopathy. Spine 1996; 21(16): pp 1877-1883.

9. Jason David Eubanks. Cervical radiculopathy : Nonoperative management of neck pain and radicular symptoms. American Family Physician. 2010; 81 (1): 33-40.

10. Michal Dwornik, Dariusz Bialoszewski, Izabela korabiewska, Zbigniew Wronski. Principles of neuromobilization for treating musculoskeletal disease. Ortopedia traumatologia Rehabilitacja, 2007; 2(6); vol9, 111-121.

11. Mortimer A J and Dyson M. The effect of therapeutic ultrasound on calcium Uptake in fibroblasts. US Med Biol. 1988; 14:499-506.

12. Mark I Johnson, Chazala Tabasam. An investigation into the analgesics effect of IFC and TENS on experimentally induced ischemic pain in otherwise pain free volunteers. Physical Therapy. 2003 Mar; 83: No 3.

13. Jason M. Beneciuk, Mark D. Bishop, Steven $\mathrm{Z}$ George. Effects of upper extremity neural mobilization on thermal pain sensitivity: A sham-controlled study in asymptomatic participants. Journal of orthopaedic and sports physical therapy. 2009; 39 (6): 428-438.

14. Christopher R Showalter, Eric Van Doorne. The role of neurodynamics in carpel tunnel syndrome with double crush syndrome. Maitland Australian Physiotherapy Seminar.

15. David S. Butler, Mobilisation of the nervous system. Churchill livingstone. 1991; Ch 13: 231-246. 
16. Dox I, Melloni BJ, Eisner GM. Melloni's Illustrated Medical Dictionary. Baltimore, Md : Williams \& Wilkins Company; 1979.

17. Wainner, R.S., Gill, H. Diagnosis and nonoperative management of cervical radiculopathy. Journal of orthopaedics and sports physical therapy. 2000; 30: 728744.

18. Radhakrishnan. K., Litchy, W.J., O'Fallon, W.M., Kurland, L.T. Epidemiology of cervical radiculopathy. A population-based study from Rochester, Minnesota, 1976 through 1990. Brain. 1987; 117: 325-335.

19. Benini A. Clinical features of cervical root compression $\mathrm{C} 5-\mathrm{C} 8$ and their variations. Neuro-Orthopedics.1987; 4 :74- 88.

20. Honet J, Puri K. Cervical radiculitis: treatment and results in 82 patients. Arch Phys Med Rehabil. 1976; 57: 12- 16.

21. Caplan L. Management of cervical radiculopathy. Eur Neurol.1995; 35: 309320.

22. Sampath P, Bendebba M, Davis JD, et al. Outcome in patients with cervical radiculopathy: prospective, multicenter study with independent clinical review. Spine. 1999; 24: 591- 597.

23. Hult L. Frequency of symptoms of different age groups and professions. In: Hirsch C, Zotterman Y, editors. Cervical pain. New York: Pergamon Press; 1971. 17-20.

24. Mohammad Taghi Joghataei, Amir Massoud Arab, Hossein Khaksar. The effect of cervical traction combined with conventional therapy on grip strength on patients with cervical radiculopathy. Clinical Rehabilitation. 2004; 18: 879-887.

25. Nanno M.Effects of intermittent cervical traction on muscle pain. Flow metric and electromyography studies of the cervical para spinal muscles. Nippon Ika Daigaku Zasshi. 1994; 61 (2): 137-47.

26. Ibrahim M. Elnaggar, Hala R. Elhabashy, Enas M. Abd El-Menam. Influence of spinal traction in treatment of cervical radiculopathy. Egypt J. Neurol. Psychiat. Neursurg. 2009; 46 (2): 455-460.

27. Prabhakar Ronald, Ramteke G. J. Cervical spinal mobilization versus TENS in the management of cervical radiculopathy: A comparative, experimental and randomized controlled trial. Indian Journal of Physiotherapy and occupational Therapy - An International journal. 2011; 5 (1): 95-99.

28. Mark I Johnson, Chazala Tabasam. An investigation into the analgesics effect of IFC and TENS on experimentally induced ischemic pain in otherwise pain free volunteers. Physical Therapy. 2003 Mar; 83:No 3.

29. Mark T. Walsh. Upper limb neural tension testing and mobilization. Journal of Hand Therapy. 2005; 18 (2): 241-258.

30. Hunt C. Peripheral nerve biomechanicsapplication to neural mobilization approach. Physical therapy reviews.2002; (7): 111-121

31. Bijur PE, Silver W, Gallagher EJ. Reliability of the visual analog scale for measurement of acute pain. Acad Emerg Med. 2001; 8 (12): 1153-7.

32. Vernon H, Mior S. Neck disability indexa study of reliability and validity. Journal of manipulative physiological therapeutics. 1991; 14(7): 409-415.

33. Steven L. Wolf, Meryl R. Gersh, Vaddadi R. Rao. Examination of electrode placements and stimulating parameters in treating chronic pain with conventional transcutaneous electric nerve stimulation (TENS). Pain. 1981; vol 11 (1): 37- 47. 